\title{
Influence of aprotinin on insulin absorption and subcutaneous blood flow in Type 1 (insulin-dependent) diabetes
}

\author{
B. Linde and R. Gunnarsson \\ Departments of Clinical Physiology and Medicine, Huddinge Hospital, Huddinge, Sweden
}

Summary. Ten normal-weight Type 1 (insulin-dependent) diabetic patients ( $12 \mathrm{~h}$ postprandial) with normal insulin requirement were given ${ }^{125}$ I-labelled soluble insulin $(10 \mathrm{U})$ in the thigh together with aprotinin $(10000 \mathrm{KIU})$ or its diluent on two consecutive mornings. Disappearance of ${ }^{125} \mathrm{I}$-radioactivity was followed continuously for $3 \mathrm{~h}$ by external detection and plasma free insulin measured by radioimmunoassay. Subcutaneous blood flow following aprotinin or diluent was studied concomitantly in the contralateral thigh by external monitoring of locally injected ${ }^{133}$ Xenon. Plasma free insulin increased significantly faster $(p<0.05)$ and the insulin area under the curve was significantly $(p<0.05)$ greater during the first hour after injection of insulin with aprotinin. Subcutaneous blood flow (rate constants for ${ }^{133}$ Xenon) was significantly higher with aprotinin $(p<0.05)$, the highest flow occurring early after injection. In conclusion, subcutaneously injected soluble insulin is more rapidly absorbed by addition of aprotinin to the insulin solution in Type 1 diabetes. Blood flow increase at the injection site may explain part of this effect.

Key words: Protease inhibitor, ${ }^{133}$ Xenon-clearance.
The protease inhibitor aprotinin has been shown to enhance insulin absorption from a subcutaneous injection site in healthy subjects when given as an additive to the insulin solution [1]. Inhibition of insulin degradation at the site of injection has been proposed as one possible mechanism behind this enhancing effect of aprotinin, but alteration in the local circulation is another suggested possibility [1]. In Type 2 (non-insulin-dependent) diabetic patients, on the other hand, no enhancing effect of the protease inhibitor on insulin absorption has been found [2]. The absorption kinetics of insulin following addition of aprotinin in Type 1 (insulin-dependent) diabetes have not yet been elucidated. The aim of the present study was therefore to investigate whether addition of aprotinin to the insulin solution enhances insulin absorption in Type 1 diabetes. We also wanted to study whether such an enhancing effect of aprotinin, if present, is coupled with an increased blood flow at the injection site.

\section{Subjects and methods}

\section{Subjects}

Ten Type 1 diabetic patients gave informed consent to participate in the study, which was approved by the Ethics Committee of Huddinge Hospital. Table 1 gives detailed clinical data on each patient. All had a normal serum creatinine value, but two patients (nos. 1 and 6) had proteinuria.

The last subcutaneous injection of insulin (soluble) was given $24 \mathrm{~h}$ before the study. The patients were admitted to the hospital $18 \mathrm{~h}$ before the study and received insulin intravenously. The infusion rate was adjusted to achieve a plasma glucose level of approximately $12 \mathrm{mmol} / 1$ by the following morning.

The subjects came to the laboratory at 0800 hours on two consecutive days, each after an overnight fast. To block thyroid uptake of ${ }^{125}$ Iodide, potassium iodide solution $(100 \mathrm{mg}$ ) was given orally $2 \mathrm{~h}$ before the study on the first experimental day, and $30 \mathrm{mg}$ on each of the 4 consecutive days.
A cannula was inserted percutaneously into an antecubital vein and blood was collected for determination of basal plasma glucose and insulin. Light weight scintillation detectors $(12.5 \times 12.5 \mathrm{~mm})$ (Leab, Mölnlycke, Sweden) were attached to the skin of each thigh, near the places to be injected, after which $0.25 \mathrm{ml}(10 \mathrm{U} ; 20 \mathrm{kBq})^{125} \mathrm{I}-$ labelled soluble insulin ( ${ }^{125}$ I-Actrapid, Novo Industri A/S, Copenhagen, Denmark) was injected subcutaneously on one side together with $0.5 \mathrm{ml}$ aprotinin $(10000 \mathrm{KIU}$, Novo Industrie GmbH Pharmaceutika, Mainz, FRG) or its diluent (thiomersal $20 \mu \mathrm{g} / \mathrm{ml}$ in saline, Pharmaceutical Department, Huddinge Hospital) in randomized order. The osmolality of the two additives was 294 and 296 mosmol for aprotinin and diluent solution, respectively. In the contralateral thigh the same additive as in the insulin solution was injected together with $0.25 \mathrm{ml}$ $(40 \mathrm{kBq}){ }^{133} \mathrm{Xe}$ in saline (Byk Malinckrodt, Petten, Holland) to study the efrect of aprotinin and diluent on the subcutaneous blood flow. The injections were performed over 2 min periods using an automatic injection device (Department of Biomcdical Engineering, Huddinge Hospital). The needle (outer diameter $0.4 \mathrm{~mm}$ ) was inserted at an angie of $45^{\circ}$ with the skin to a depth of $5 \mathrm{~mm}$ beneath the skin surface. Registration of radioactivity started immediately after the first injection and was continued for $3 \mathrm{~h}$ with the patient supine. During the measurements the room temperature was $24 \pm 1{ }^{\circ} \mathrm{C}$. The two scintillation detectors were coupled to a four channel spectrometer (ND 600, Nuclear Data, Schaumburg, Illinois, USA) set to measure the photopeaks of ${ }^{133} \mathrm{Xe}$ and ${ }^{125} \mathrm{I}$. Counts were accumulated during consecutive $60 \mathrm{~s}$ intervals and displayed on the screen of the spectrometer. Venous blood was sampled at 15 -min intervals during the first hour and at 1.5, 2 and $3 \mathrm{~h}$ following injection and analyzed for plasma glucose and radioimmunoreactive free insulin.

\section{Analytical procedures}

Plasma glucose was analyzed by the glucose oxidase method on a glucose analyzer (Beckman Instruments, Fullerton, California, USA). Plasma free insulin was determined by radioimmunoassay [3] after immediate pretreatment of the plasma with polyethylene glycol [4]; all samples obtained from one and the same patient were analyzed in the same assay. The intra-assay method error was 3\%.

\section{Data analysis}

Subcutaneous blood tlow was followed by local clearance of ${ }^{133} \mathrm{Xe}$ [5]. For the calculation of blood flow in absolute units, the partition coef- 
Table 1. Characteristics and clinical data on the diabetic patients studied

\begin{tabular}{|c|c|c|c|c|c|c|c|c|}
\hline \multirow{2}{*}{$\begin{array}{l}\text { Patient } \\
\text { no. }\end{array}$} & \multirow[t]{2}{*}{ Sex } & \multirow{2}{*}{$\begin{array}{l}\text { Age } \\
\text { (years) }\end{array}$} & \multirow{2}{*}{$\begin{array}{l}\text { Duration } \\
\text { of diabetes } \\
\text { (years) }\end{array}$} & \multirow{2}{*}{$\begin{array}{l}\text { Body mass } \\
\text { index } \\
\left(\mathrm{kg} / \mathrm{m}^{2}\right)\end{array}$} & \multirow{2}{*}{$\begin{array}{l}\text { Plasma } \\
\text { C-peptide } \\
\text { (nmol/1) }\end{array}$} & \multicolumn{2}{|c|}{ Insulin dose } & \multirow[t]{2}{*}{ Eye examination } \\
\hline & & & & & & $\mathrm{U} /$ day & $\mathrm{U} / \mathrm{kg}^{-1} \cdot \mathrm{d}^{-1}$ & \\
\hline 1 & $\mathbf{M}$ & 45 & 24 & 19.5 & $<0.05$ & 28 & 0.46 & Proliferative retinopathy \\
\hline 2 & $\mathbf{M}$ & 38 & 11 & 24.2 & $<0.05$ & 52 & 0.67 & Background \\
\hline 3 & $\mathbf{M}$ & 23 & 3 & 22.6 & $<0.05$ & 68 & 1.01 & Normal \\
\hline 4 & $\mathbf{M}$ & 40 & 7 & 23.9 & 0.08 & 20 & 0.29 & Normal \\
\hline 5 & $\mathrm{~F}$ & 24 & 22 & 22.1 & $<0.05$ & 56 & 0.89 & Background \\
\hline 6 & M & 53 & 26 & 23.5 & $<0.05$ & 62 & 0.97 & Proliferative retinopathy \\
\hline 7 & $\mathrm{~F}$ & 54 & 30 & 21.7 & $<0.05$ & 32 & 0.60 & Background \\
\hline 8 & $\mathrm{~F}$ & 24 & 20 & 23.6 & $<0.05$ & 32 & 0.56 & Proliferative retinopathy \\
\hline 9 & M & 41 & 3 & 23.4 & 0.30 & 24 & 0.32 & Normal \\
\hline 10 & M & 35 & 6 & 22.7 & $<0.05$ & 44 & 0.61 & Normal \\
\hline $\begin{array}{l}\text { Mean } \\
\pm \text { SEM }\end{array}$ & & $38 \pm 4$ & $15 \pm 3$ & $22.7 \pm 0.4$ & & $42 \pm 5$ & $0.64 \pm 0.08$ & \\
\hline
\end{tabular}
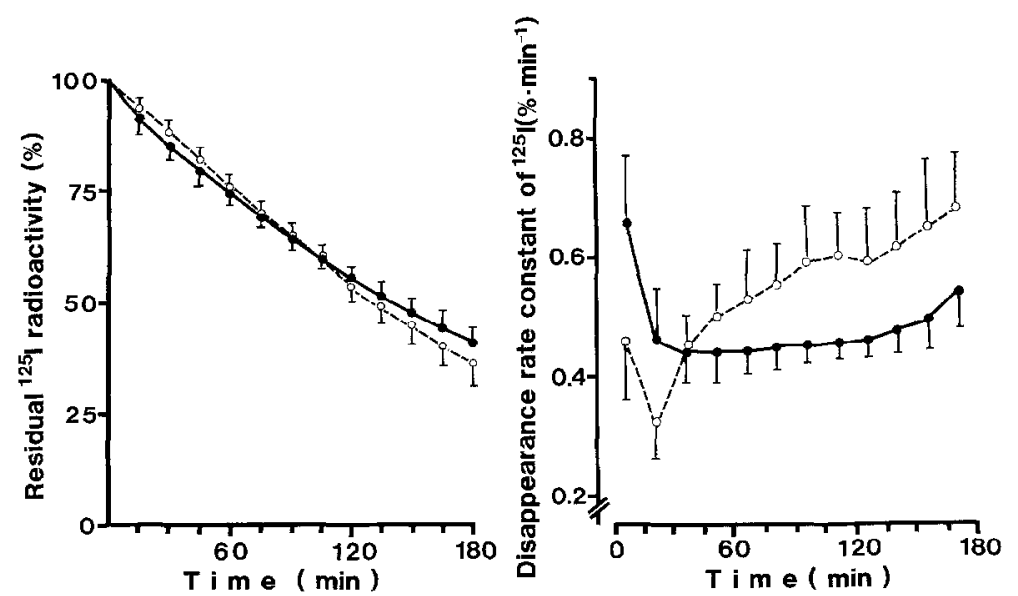

Fig. 1. Residual ${ }^{125} \mathrm{I}$-radioactivity after subcutaneous injection of ${ }^{125} \mathrm{I}$-labelled soluble porcine insulin $(10 \mathrm{U})$ with aprotinin $(-\rightarrow)$ ) or diluent $(O----O)$. First order disappearance rate constants of ${ }^{125}$ I during consecutive 15 -min periods in the two groups. During the first $30 \mathrm{~min}$ the rate constants in the aprotinin group tended to be higher than those in the diluent group $(p=0.07)$

ficient for ${ }^{193} \mathrm{Xe}$ in the tissue is needed. Addition of aprotinin or diluent to the ${ }^{133} \mathrm{Xe}$ solution will unpredictably alter this coefficient. Therefore, only rate constants are given in this study as an index of the subcutaneous blood flow and conclusions have been drawn, not from absolute rate constants, but from within and between group comparisons. An Apple II microcomputer (Apple Computer Inc., Cupertino, California, USA) was used to calculate the fractional disappearance rates of ${ }^{133} \mathrm{Xe}$ and ${ }^{125} \mathrm{I}$ using linear regression analysis of the natural logarithms of the counts accumulated over consecutive 15-min intervals. The insulin area-under-curve was calculated by trapezoidal integration of the incremental values.

\section{Statistical analysis}

Significant differences between groups were determined by using the paired t-test. All data are presented as mean \pm SEM.

\section{Results}

\section{Absorption kinetics of ${ }^{125}$ I-radioactivity}

During the initial $15 \mathrm{~min}$ following injection the absorption rate of ${ }^{125} \mathrm{I}$ in the aprotinin group was higher than later after injection, when the rates stabilized (Fig.1). In the diluent group, the rate constants tended to be lower than those in the aprotinin group during the first $30 \mathrm{~min}$ after injection $(p=0.07)$, but the reverse pattern was seen later after injection. The time until $50 \%$ of the radioactivity was eliminated was, however, similar in the aprotinin and diluent groups, $143 \pm 13$ and $138 \pm 16 \mathrm{~min}$ respectively.

\section{Plasma immunoreactive free insulin and C-peptide}

Plasma free insulin was significantly higher in the aprotinin compared to the diluent group during the first 45 min following injection after which the two curves were superimposable (Fig. $2, p<0.05$ ). There was a significant difference between the areas under the curves above basal level in the aprotinin and diluent groups from time of injection up to $60 \mathrm{~min}$ following injection (Fig. $2 ; p<0.05$ ). In the two patients with residual insulin production the plasma C-peptide levels were similar on the 2 study days and did not change after insulin injection.

\section{Subcutaneous blood flow}

Disappearance of ${ }^{133} \mathrm{Xe}$ from the depots of aprotinin and diluent is shown in Figure 3. The first order rate constants in the aprotinin group were significantly higher than those in the diluent group during the entire period of registration $(p<0.05)$. This difference between the two groups was most pronounced during the first hour following injection.

There was a low insignificant correlation between the disappearance rate constants of ${ }^{125} I$ and ${ }^{133} \mathrm{Xe}$ as well as between the plasma insulin areas and the rate constants of ${ }^{133} \mathrm{Xe}$. 


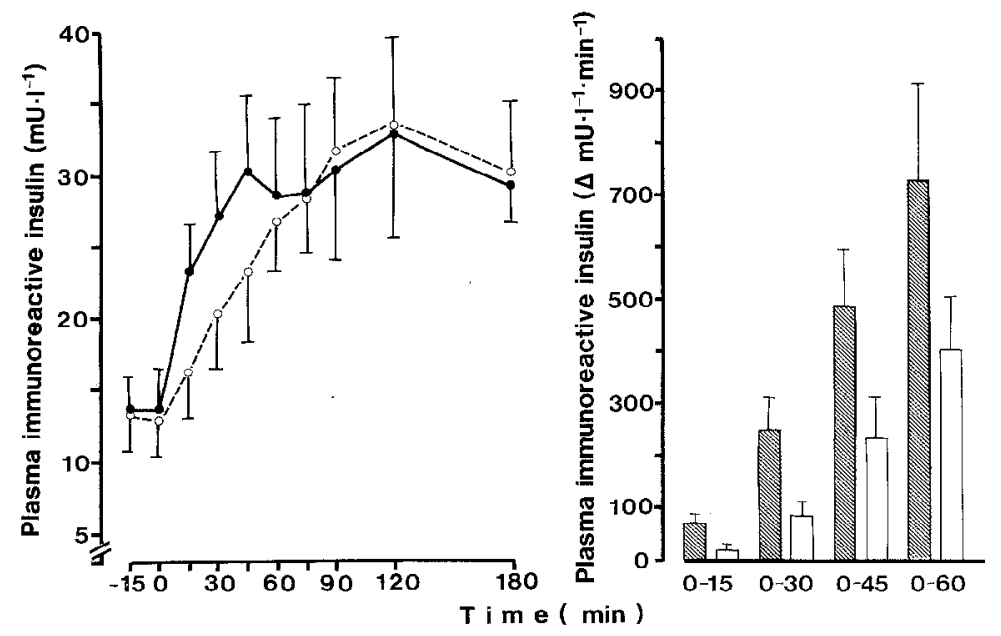

Fig. 2. Plasma immunoreactive free insulin after subcutaneous thigh injection of ${ }^{125}$ I-labelled soluble porcine insulin $(10 \mathrm{U})$ with aprotinin $(\longrightarrow)$ or diluent $(\mathrm{O}---\mathrm{O})$. The values in the aprotinin group were significantly higher than those in the diluent group during $45 \mathrm{~min}$ following injection $(p<0.05)$. Area-under-curve above basal plasma immunoreactive free insulin during the time periods indicated in the figure in the aprotinin and diluent $\square$ groups. During all four time periods there was a statistically larger area in the aprotinin group $(p<0.05)$

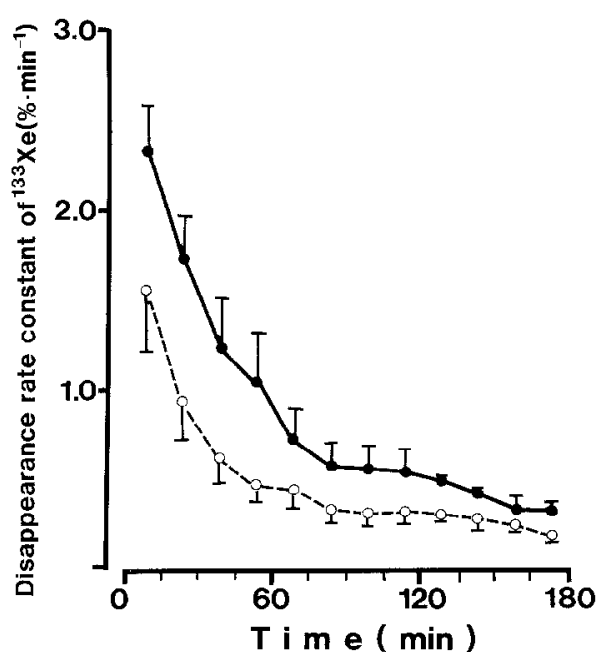

Fig.3. First order disappearance rate constants of ${ }^{133} \mathrm{Xe}$ during consecutive 15-min periods following subcutaneous injection with aprotinin (-) or diluent $(\mathrm{O} \ldots \mathrm{O})$ in the contralateral thigh. The rate constants in the aprotinin group were significantly higher than those in the diluent group during the entire period of registration $(p<0.05)$

\section{Plasma glucose}

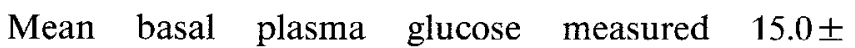
$0.9 \mathrm{mmol} / 1$ in the aprotinin group and $13.5 \pm$ $1.3 \mathrm{mmol} / \mathrm{l}$ in the diluent group (NS). Following insulin injection the falls in plasma glucose were similar.

\section{Discussion}

Addition of the protease inhibitor aprotinin to the insulin solution induced a similar early enchancing effect on the absorption of insulin from its injection site in our group of Type 1 diabetic patients, as previously reported for healthy subjects [1]. Thus, we found a significantly earlier insulin entry into the circulation. The disappearance rate of the radiolabelled insulin from the injection site was also higher with aprotinin early after injection, although the difference was not statistically significant. The most likely explanation for this minor discrepancy between the two methods used to study insulin absorption is a statistical type 2 error. However, it cannot be entirely excluded that the discrepancy could be due to the fact that the two methods are not fully comparable as a measure of insulin absorption, as has been discussed earlier [6].

The possibility that the early enhancement of insulin absorption by aprotinin could be due to effects on the circulation at the injection site was elucidated by injecting the flow indicator ${ }^{133} \mathrm{Xe}$ in the contralateral thigh together with aprotinin or diluent. There was in fact a significantly higher elimination rate of ${ }^{133} \mathrm{Xe}$ in the aprotinin group during the whole measurement. Since the elimination of an inert freely diffusible substance is influenced not only by the local blood flow but also by the physical solubility of the substance in tissue relative to blood, the so called partition coefficient [7,8], a difference in this coefficient would theoretically cause a difference in the elimination rate between the groups. However, since the volume of the injectates was standardized and the osmolality of the additives was found to be similar in the present study, it is unlikely that the solubility for ${ }^{133} \mathrm{Xe}$ would differ significantly between the two experimental groups. Therefore, the faster elimination rate of ${ }^{133} \mathrm{Xe}$ with aprotinin is most probably due to a higher blood flow in this group.

By using a photoelectric measuring principle, hyperaemia in the tissues beneath the measuring probe following the injection of aprotinin has also recently been reported [9]. The photoelectric technique, however, does not allow discrimination between blood flow changes in the skin and the subcutaneous tissue. Therefore, the flow increase registered by Williams et al. [9] might well have been an effect of the injection trauma in the cutaneous tissues. The local ${ }^{133} \mathrm{Xe}$ clearance technique, on the other hand, reflects the circulation selectively within the depot area and, thus, shows that blood flow was indeed higher in this area when aprotinin was given with the insulin.

There was a greater difference in the elimination rates of ${ }^{133} \mathrm{Xe}$ between the two groups during the first hour after injection than later, indicating a more pronounced hyperaemia in the aprotinin group early after injection. This coincided in time with the enhanced insulin absorption in this group, which might imply a causal relationship between increased blood flow and 
insulin absorption. However, no significant correlation was found between the rate constants of ${ }^{125}$ I-radioactivity and ${ }^{133} \mathrm{Xe}$ nor between the plasma insulin areas and the rate constants of ${ }^{133} \mathrm{Xe}$. Although some authors have found a correlation between subcutaneous blood flow and insulin absorption [10,11] others [12] have found this to be true only under basal blood flow conditions, whereas during higher flow rates the influence of other factors became more important. The absence of such a correlation could have several explanations and does not exclude the possibility that an increase in blood flow may have contributed to the enhancement of insulin absorption by aprotinin.

It is obvious that the enhancing effect of aprotinin was not quantitatively important enough to influence plasma glucose significantly in our diabetic subjects. Berger et al. [1] found a significantly earlier onset of the hypoglycaemic action of insulin following aprotinin in their group of healthy volunteers. However, Type 1 diabetic patients are on the whole more insulin resistant than healthy subjects [13]. This may be especially true at the plasma glucose levels found in the present study at the beginning of the investigation. A recent study by Lunetta et al. [14] showed no effect on plasma glucose of aprotinin compared with diluent in Type 1 diabetes, which is in agreement with our results. However, that study did not report data on plasma insulin and, thus, an effect of aprotinin similar to that found in the present study may also have been present.

Deckert et al. found no effect of aprotinin on plasma insulin in Type 2 (non-insulin-dependent) diabetic patients given approximately $4 \mathrm{U}$ soluble insulin [2]. The discrepancy between the results from the present study and that of Deckert et al. [2] might be due to the different insulin doses given. Lower doses are absorbed more rapidly [15] and it is possible that an enhancing effect of aprotinin might be more difficult to detect at a higher basal absorption rate. Conversely, it seems possible that patients requiring high doses of insulin would have a more pronounced effect on insulin absorption than patients using lower doses by the addition of an agent causing hyperaemia at the site of injection. High dose requiring patients also often receive more concentrated insulin solutions which per se are known to be absorbed more slowly [16]. In fact, it has been shown that Type 1 diabetic patients requiring very high doses of insulin by the subcutaneous route can reduce their insulin dose considerably by the addition of aprotinin to the insulin solution [17]. Inhibition of insulin degradation at the site of injection has been proposed as one possible mechanism behind the beneficial effect of aprotinin in these patients [17]. On the basis of the present results, however, it may be suggested that at least part of the effect of aprotinin in these patients requiring unusually high doses of insulin could be due to hyperaemia at the injection site.

In summary, the present study has shown an enhancing effect of the protease inhibitor aprotinin on the absorption of soluble porcine insulin from a subcutane- ous injection site after injection in Type 1 diabetic subjects. Higher subcutaneous blood flow was also found following aprotinin and may explain part of this enhancing effect.

Acknowledgements. This study was supported by grants from the Swedish Medical Research Council, project no. 7154, the Swedish Diabetes Association, Åke Wibergs Stiftelse and the Karolinska Institute. We are grateful for the expert laboratory assistance of H. Eriksson and K. Föjer and the secretarial assistance of I.Sigurdson.

\section{References}

1. Berger M, Cüppers HJ, Halban PA, Offord RE (1980) The effect of aprotinin on the absorption of subcutaneously injected regular insulin in normal subjects. Diabetes 29:81-83

2. Deckert T, Hansen B, Lauritzen T, Sandahl Christiansen J (1981) Subcutaneous degradation of insulin. Diabetologia 21:161-162

3. Heding LG (1972) Determination of total serum insulin (IRI) in insulin-treated diabetic patients. Diabetologia 8: 260-266

4. Kuzuya H, Blix PM, Horwitz DL, Steiner DF, Rubenstein AH (1976) Determination of free and total insulin and C-peptide in insulin-treated diabetics. Diabetes 26: 22-29

5. Larsen OA, Lassen NA, Quaade F (1966) Blood flow through human adipose tissue determined with radioactive xenon. Acta Physiol Scand 66: 337-345

6. Berger M, Cüppers HJ, Hegner H, Jörgens V, Berchtold P (1982) Absorption kinetics and biologic effects of subcutaneously injected insulin preparations. Diabetes Care 5: 77-91

7. Kety SS (1949) Measurement of regional circulation by the local clearance of radioactive sodium. Am Heart J 38: 321-328

8. Sejrsen P (1971) Measurement of cutaneous blood flow by freely diffusible radioactive isotopes. Costers Bogtrykkeri, Copenhagen, pp 1-38

9. Williams G, Pickup JC, Bowcock S, Cooke E, Keen H (1983) Subcutaneous aprotinin causes local hyperaemia. Diabetologia 24: 91-94

10. Kolendorf K, Bojsen J, Nielsen SL (1979) Adipose tissue blood flow and insulin disappearance from subcutaneous tissue. Clin Pharmacol Ther 25: 598-604

11. Lauritzen T, Binder C, Faber OK (1980) Importance of insulin absorption, subcutaneous blood flow, and residual beta-cell function in insulin therapy. Acta Paediatr Scand (Suppl) 283:81-84

12. Hildebrandt P, Birch K, Sestoft L, Nielsen SL (1983) Non-linear relationship between subcutaneous blood flow and insulin absorption. Diabetologia 23: 174

13. DeFronzo RA, Hendler R, Simonson D (1982) Insulin resistance is a prominent feature of insulin-dependent diabetes. Diabetes 31 : 795-801

14. Lunetta M, Leonardi R, Rapisarda S, Palermo F, Mughini L (1984) Aprotinin administered together with insulin has no effect on blood glucose levels in type 1 diabetics. IRCS Med Sci 12: 23

15. Hildebrandt P, Birch K, Sestoft L, Vølund A (1984) Dose-dependent subcutaneous absorption of porcine, bovine and human NPH-insulins, MC. Acta Med Scand 215: 69-73

16. Hildebrandt P, Sestoft L, Nielsen SL (1983) The absorption of subcutaneously injected short-acting soluble insulin: influence of injection technique and concentration. Diabetes Care 6:459-462

17. Freidenberg GR, White N, Cataland S, O'Dorisio TM, Sotos JF, Santiago JV (1981) Diabetes responsive to intravenous but not subcutaneous insulin: Effectiveness of aprotinin. N Engl J Med 305: $363-368$

Received: 16 October 1984

and in revised form: 9 May 1985

Dr. Birgitta Linde

Department of Clinical Physiology

Huddinge Hospital

S-14186 Huddinge

Sweden 